\title{
TRES VÉRTICES ATLÁNTICOS: PERFILES, DISLOCACIONES Y
}

PARALAJE

\section{Three Atlantic angles: profiles, dislocations and parallax}

\author{
Ignacio Irazuzta ${ }^{1}$ \\ Tecnológico de Monterrey (México) \\ ignacio.irazuzta@gmail.com
}

Palabras clave

América Latina

Investigación

Ciencias Sociales

Dislocaciones

Paralajes

Diáspora

\section{Keywords}

Latin America

Research

Social Sciences

Dislocations

Parallax

Diaspora

\section{Resumen}

Desde la temática general de académicos latinoamericanos desempeñando su profesión y construyendo sus objetos de investigación a partir de algún desplazamiento fuera de su lugar de origen, el artículo presenta dos partes diferenciadas. En la primera, se hace una caracterización tipológica de las formas históricas de salidas en América Latina para trazar luego un perfil del académico emigrado actual que, aunque en ocasiones seguramente sesgado por la experiencia personal del autor, se pretende también típico ideal. La segunda parte, que se centra en el recorrido biográfico por las formas del hacer académico, reconstruye las dislocaciones del autor desde los tres vértices geográficos y las dos fronteras disciplinarias que le son propios para componer un paralaje que va modificando los objetos de investigación según sus posiciones.

\section{Abstract}

The article builds on the general topic of Latin American academics living their profession while building their research objects from the experience of displacement, thus leaving their place of origin. First, I make a typological characterization of the historical forms of the intellectual "way out" in Latin America. Then, I draw a profile of the current emigrated academic, which intends to be an ideal type; although it may be biased by my personal experience. Secondly, the article focuses on my biography through my own academic practices, rebuilding my displacements from three geographic angles and the boundaries of the academic disciplines in which I was formed. The latter serves to compose a parallax that shapes the research objects according to its positions.

Irazuzta, I., 2015, "Tres vértices atlánticos: perfiles, dislocaciones y paralaje", en Papeles del CEIC, vol. 2015/1, no 117, CEIC (Centro de Estudios sobre la Identidad Colectiva), Universidad del País Vasco, http://dx.doi.org/10.1387/pceic.13162

\footnotetext{
${ }^{1}$ Agradezco los sugerentes y atinados comentarios de los evaluadores de Papeles del CEIC, los que han contribuido a mejorar este artículo. Mi gratitud es también hacia María Martínez, que me ha proporcionado interesantes referencias bibliográficas.
} 
"What should they know of England who only England know?"

Joseph Rudyard Kipling

En 1932, luego de que miembros de la Fundación Rockefeller conocieran los resultados de la investigación sobre la población desempleada de Marienthal, Paul Lazarsfeld obtiene una beca de esa fundación para viajar a los Estados Unidos y visitar alli algunos centros de investigación. Ese primer contacto con América del sociólogo vienés lo volverá a traer a este lado del Atlántico para desarrollar una extensa y fructífera carrera sobre la que el mismo Lazarsfeld no ahorra palabras en relatar en una autobiografía intelectual publicada en más de una ocasión ${ }^{2}$. Dice allí que lo que justifica tal tipo de textos es al menos una de las siguientes tres condiciones: cuando quien la escribe es una personalidad de grandes logros; cuando la posición de quien enuncia se ha situado cercana a grandes acontecimientos o personajes o cuando, por circunstancias fortuitas, el relato puede ser considerado como el de "un caso" más o menos representativo de una circunstancia histórica o proceso de interés.

Esta última condición, que además Lazarsfeld contempla con especial apetencia sociológica puesto que los materiales personales han sido desde su época nutrientes para mucha investigación social, es la que escoge el sociólogo y matemático austríaco para encuadrar su autobiografía. Pero a esta perspectiva del "testigo", le agrega Lazarsfeld la del "experto", calificativo que, aunque no define con precisión, cabe presumir que refiere a una especialidad académica que le permite encuadrar su recorrido vital dentro de unas pautas que dan coherencia a su descripción. Es en cambio específico en lo que concierne al carácter de "testigo" de esta fusión: considera su presencia protagonista de un trasiego intelectual entre Europa y América en un momento en el que la ciencia social del viejo continente era predominantemente ensayística y especulativa y en el que el nuevo buscaba impulso empírico para los, a partir de entonces, prolíficos institutos de investigación social norteamericanos. La figura de Lazarsfeld, matemático de formación, con incursiones en la psicología y con trabajos importantes en sociología, conformaba un cuadro más que atrayente para los impulsores de la ciencia social estadounidense. Bajo la impronta de

\footnotetext{
${ }^{2}$ Primero en 1968, como capítulo del segundo volumen de Perspectives in American History; luego en el texto de D. Fleming y D. Bailyn, Intelectual Migration: Europe and America, 1930-1960 (Cambridge, Harvard University Press, 1969) y después en español, de donde es tomada aquí la referencia (Lazarsfeld, 2001).
} 
"positivista europeo" en América, Lazarsfeld reconstruye en el texto un estilo de investigación y una labor de gestión académica que desplegará en varios institutos de investigación social.

Salvando las distancias entre unos lugares y otros, pero sobre todo entre el calibre de una trayectoria académica que podría considerarse de grandes obras y otra - la del que esto escribe- que, a lo más, compite en los términos de categorías curriculares inferiores, haré propia esta perspectiva del testigo experto de Lazarsfeld para relacionar mi propia experiencia biográfica con lo que son y han sido mis objetos de investigación. Pero para ser más preciso, quizá convenga revisar y hacer alguna aclaración respecto a esa condición de testigo. No se trata con ello de asestar la visión hacia un acontecer certero y objetivo que rodea la posición desde la que se enuncia y la autoriza para emitir desde allí el relato. Más bien, lo que me propongo es reconstruir una experiencia, mi experiencia, no como aquello que se tiene sino como el análisis de un proceso de construcción de subjetividad (Scott, 1992), una suerte de sociología de sí que en este caso sitúo en la vía de una trayectoria académica que transcurre a través de los límites de tres comunidades nacionales, de un lado y otro del Atlántico. Entiendo cada uno de estos tres vértices atlánticos como enclaves de inclusión-exclusión, que constituyen los puntos de un paralaje e imprimen esa diferencia en la subjetividad que, se presume, operan una modificación en la posición desde la cual los objetos de investigación se hacen y hacen a aquel a quien los hace.

El texto que sigue es el resultado de la dificultad de tratar de ver, analizar y escribir lo que de subjetivo hay en los objetos de estudio que uno va construyendo. Tiene dos partes bien diferenciadas que revelan esa dificultad y que corresponden a diferentes momentos de elaboración. La primera es un texto producido durante la discusión del proyecto, cuando intercambiábamos impresiones entre Gabriel Gatti y Danilo Martuccelli sobre si era posible pensar en conjunto las experiencias de académicos latinoamericanos fuera de Latinoamérica y reunir algunas de ellas en un texto colectivo. Barajando las nociones de campo, posiciones o perfiles de lo que asumimos de entrada como una figura o personaje protagonista de tales experiencias, escribí lo que aquí presento en primer lugar y que es una serie de consideraciones sobre las "marcas de salida" de este personaje, de los hitos históricos que hacen a su manifestación actual y del entorno y las prácticas que acompañan a unas formas y otras de desplazamiento. 
La segunda parte se sitúa en el yo de esas prácticas y formas desplazadas. Es el relato de mi experiencia, de mi modo de ver y construir, desde las diferentes perspectivas que me generan unos lugares y otros, mis objetos de estudio o temas de investigación. También desde allí, desde estos lugares-posiciones que son tres, el texto describe las diferentes modalidades de agenciamiento académico, el terreno y las estructuras de oportunidades que observo y vivo en cada sitio. Cada una de estas partes tiene por tanto un diferente registro de enunciación. En cierta medida por la dificultad de fusionar los dos momentos de estas dos partes del artículo y en parte también para resaltar esta diferencia, he preferido conservar sus formas originales en este sentido.

\section{EL ATLÁNTICO Y LAS MARCAS DE SALIDA}

Lo que otorga especificidad a los personajes sobre los que nos convoca a reflexionar Papeles del Ceic es el hecho de poder dar cuenta de itinerarios atravesados por socializaciones académicas cruzadas entre América Latina y Europa, pero ¿qué podemos decir acerca de lo que define su profesión, de sus referentes del pasado, de su estirpe, y de las condiciones de su presente? Aludimos a esta figura ${ }^{3}$ con palabras como investigadores, académicos o intelectuales. Difícil denominación para un personaje que no es "personalidad" pero que se define en buena medida sobre referentes pasados o consolidados que lo fueron o lo son, personalidades que también ejercieron o ejercen su oficio desde alguna relación de exterioridad con América Latina y que, en buena medida, han hecho o hacen de esta relación parte esencial de su producción intelectual. Estas personalidades pasadas o consolidadas no son un modelo, tampoco una réplica de los actuales. Son, en todo caso, el componente diacrónico de un fenómeno de larga trayectoria en la región. Así pues, aún sin sentido compartido, lo que este personaje puede ofrecer en su perfil son gruesas capas históricas de generaciones de letrados que, por unos motivos $u$ otros, han mirado desde afuera a América Latina y que constituyen el

\footnotetext{
${ }^{3}$ Figura, personaje o personaje-figura. Ambas imágenes pueden estar sobradas de motivos sociológicos. Utilizo aquí estas palabras, sin embargo, por motivos más mundanos: primero por lo que siento como un déficit o aplazamiento de definición que nos permita arribar a un nombre para referir a ese objeto que es en parte en primera persona; segundo porque dicho así, alternativamente - bien figura, bien personaje-, o con guión - personaje-figura- me permite sortear esa cuestión de género que ha de ser dicha y escrita y sobre la que casi siempre se cierne un estilo que tiende a la inercia, una gramática.
} 
antecedente de carisma de su rutinización profesional actual. Los ejemplos de estas figuras consagradas abundan pero las formas históricas de su desplazamiento han sido fundamentalmente tres: viajes, exilios y emigraciones. $Y$, aunque a veces yuxtapuestas en el tiempo, me atrevería a hacer de este orden una secuencia.

Sin lugar a dudas, el viaje guarda con respecto a América un antecedente fundador. Desde aquellos más remotos de conquista, pasando por los de Humboldt o Tocqueville, en una de las direcciones del ir y venir, y hasta los protagonizados por la élite letrada, autora de libros y de estados en la otra dirección, los viajes inauguran una perspectiva extrañada que casi siempre tiene al Atlántico como centro de gravitación de la modernidad y al barco como su artífice, su medio (Gilroy, 1993). La distancia hace tanto a los viajes como a una forma de conocimiento en la que, en estas primeras perspectivas, origen y destinos están separados por una relación de extrañamiento profundamente signada por una desigualdad colonial que inspira importaciones y adaptaciones de filosofías y proyectos políticos y civilizatorios para América y de la que sobradas muestras da el implante y difusión del positivismo en América Latina.

El exilio se corresponde en algunos de sus jalones históricos con los últimos de estos viajes reseñados. Es una figura de alejamiento forzado, involuntario por tanto, políticamente motivado, casi siempre presente en la región y una de las modalidades de conexión entre Europa y América y entre diferentes países de América. Imprime formas a intelectualidades de aquí y de allá y afecta tanto a esa figura más moldeada del intelectual como a otras más aferradas a las modalidades institucionalizadas del saber. Ha habido y hay formidables, copiosas e ingentes producciones de exilios en América Latina, al punto de dar cabida a tipos de exilio para los que el desplazamiento físico no es condición necesaria, como sí en cambio lo fue el desplazamiento subjetivo para esas formas de "exilio interior" que produce sobre todo la década de los setenta en América Latina. De una manera o de otra, la del exilio es la figura referencial para nuestro personaje presente, bien por filiación intelectual, cultural o directamente filial.

Si el exilio se corresponde con momentos de vivacidad de la política, o del reverso de esa vivacidad producto de un clímax que da paso al terror y al terror del ostracismo, la emigración se relaciona con ese otro tipo de impulso que, para simplificar las causas del movimiento, se entiende como "económico" pero que, sin dudas, admite esa amplia variedad de matices 
que se suelen endosar a "lo cultural", a esa batería de antecedentes históricos que conforma imaginarios de traslación en los que mucho colaboran las otras dos formas de desplazamiento aludidas. Considerada en el campo del saber, especialmente de las ciencias sociales, la migración de los años noventa -esa que, se podría decir, reúne el grueso social de nuestro interés - es hija de la generación del exilio; está simbólicamente preñada por ésta. Para la generación contemporánea de latinoamericanos fuera de Latinoamérica el exilio hace a una épica del estar, decir y hacer desde afuera.

Pues bien, para dibujar las formas de los "quienes" del momento actual propongo recomponer por puntos -al menos los que me represento yo como principales - los contornos de nuestra figura. Procederé para ello a la manera convencional de la Sociología, es decir, intentando buscar las señas diferenciales del presente en el repaso agitado de un pasado borroso, viendo allí sólo aquellas marcas que dibujan las "formas más estructuradas" (Weber, 2001: 112) de la historia a partir de los modos de desplazamiento descritos. Modo sociológico, pues: la operación es la de simplificación del pasado y aplazamiento del futuro para procurar mayor cabida al análisis del presente.

\subsection{Los usos de la historia}

El personaje actual se inscribe en la historia de los modos de alejamiento descritos y en las perspectivas que estos modos producen: tiene historias de viajes con sentido del desplazamiento, con sentidos tan seducidos como colonizados por el pensamiento del norte; también historias de exilios o "simples" emigraciones, o de emigraciones que se transforman en exilios, o de exilios que ya no encuentran posibilidad de desexilio... Nuestro personaje tiene incluso estirpe en ese cúmulo histórico de traslado que es históricamente frecuente en América Latina. Alcurnias que produce la propia operación de la calificación del pasado que hace la historia para producirse a sí misma en efectos sociales presentes. El personaje en cuestión es un acumulador de pasados particular: encarna en sí un mestizaje histórico que lo hace analista de dos mundos, o de uno y otro pero siempre con una relativa perspectiva de alteridad. Por propio efecto del traslado mantiene en cierto desuso la historia aprendida en origen y hace un uso distinto de la adquirida en destino. Es capaz de posarse con cierta liviandad sobre las historias de esos otros lugares, historias con las que, al menos en principio, guarda alguna relación de extrañamiento. Una 
relación que puede incluso recobrar para su lugar de origen reservándose para sí mismo una perspectiva de atalaya tan privilegiada como cuestionada. De su privilegio da cuenta una extensa tradición occidental que habla del lugar de observación y del soberanismo de la mirada distante. Como en Maquiavelo generando saberes para Lorenzo de Médicis, a partir de una composición de lugar, le parece ver "la verdad de las cosas y la importancia de la materia" haciendo como los pintores, "que van a dibujar los valles desde las montañas y las montañas desde los valles para que ambos se descubran ante sí de un modo claro, distinto, completo y perfecto" (Maquiavelo, 1992: 3). No es por ello un ingenuo creyente de la objetividad de la realidad social pero parece especialmente predispuesto al ejercicio del "paralaje", es decir, está en condiciones ventajosas para cambiar de lugar de observación y ver así cambiar a su objeto o resignificar la objetividad de las cosas y reafirmar de ese modo su carácter "contingente y disputable" (Foster, en Arditi, 2010). No sólo por formación profesional sino por su especial predisposición a esa composición de lugares, nuestro personaje encarna especialmente el forastero de Schutz: es extraño a las definiciones autóctonas de la realidad; produce una "dislocación de sus perfiles de significatividad" utilizando "una anonimia y tipicidad de los actos sociales que no es la de los miembros del endogrupo"; cuestiona lo que "va de suyo" de la realidad y ésta se le torna constantemente problemática en tanto que producida desde el desarraigo (Schutz, 1974: 102-105).

\subsection{La épica del exilio}

Efectivamente, parece propia de nuestro personaje una reflexividad desarraigada que, no obstante, echa como decíamos raíces en esas formas de alejamiento de larga historia: viajes, emigraciones pero fundamentalmente exilios. Para la versión contemporánea del emigrado latinoamericano, académico o investigador, el exilio domina la épica de las perspectivas del afuera, no sólo por la especificidad de la región sino por la entidad de "tema universal" que tiene el que relaciona a la literatura con el exilio. Se podría decir que el exilio es la anomalía más normal de la escritura. Y en América Latina imprime su sello como origen y como destino: desde su protagonismo en la fundación de naciones por parte de quienes regresaban de su exilio europeo en tiempos en los que la profesión de escritor no se distinguía mucho de la política y cargaba con la misión de producir civilización en "la nada desértica o salvaje", hasta los más recientes de la década de los setenta que, aún cuando protagonizados por 
una generación que se cimienta en la crítica de aquella otra de afán civilizatorio ${ }^{4}$, contribuye a la gesta de heroicidad en las formas de estar, ser y hacer desde afuera. El exilio impregnó gran parte de la literatura latinoamericana, incluso más allá de sus condiciones físicas de exterioridad: la figura del exilio exterior e interior dominó en importante medida las concepciones del intelectual durante los tiempos duros o nulos de la política, en el período de las dictaduras ${ }^{5}$; ofició incluso un cambio de estatus en antiguos emigrantes e hizo de la literatura un arma de combate. Y para muestra un Cortázar: "Y si quienes me cerraron el acceso cultural a mi país piensan que han completado así mi exilio, se equivocan de medio a medio. En realidad me han dado una beca de full-time, una beca para que me consagre más que nunca a mi trabajo, puesto que mi respuesta a ese fascismo cultural es y será multiplicar mi esfuerzo junto a todos los que luchan por la liberación de mi país. Desde luego no voy a dar las gracias por una beca de esa naturaleza, pero la aprovecharé a fondo, haré del disvalor del exilio un valor de combate" (1984: 13).

No ya desde sino hacia América Latina, menos cerca de la literatura, más de las profesiones que pretendemos entender pero igualmente atravesado por la distancia hiriente del exilio está el proceso de institucionalización de las ciencias sociales en la región. El caso de México es especialmente ilustrativo de la cosa. La sucesiva acogida del exilio político es de un protagonismo fundamental en la creación de los centros públicos de investigación: primero, durante los años treinta, el exilio español que fundará La casa de España y luego el Colegio de México en 1940; posteriormente los científicos sociales latinoamericanos (Véjar PérezRubio, 2008) que, desde la década del setenta, encontrarán refugio también en el COLMEX y mayormente en las universidades públicas. El COLMEX está singularmente marcado en su fundación por los

\footnotetext{
${ }^{4}$ Y por ello, como me lo ha señalado Pablo Francescutti, en tanto que Europa marcaba un horizonte temporal de civilización, los viajes de esta generación eran "auténticas travesías al futuro".

5 "Al tocar el problema del escritor exilado, me incluyo actualmente entre los innumerables protagonistas de la diáspora. La diferencia está en que mi exilio sólo se ha vuelto forzoso en estos últimos años; cuando me fui de la Argentina en 1951, lo hice por mi propia voluntad y sin razones políticas o ideológicas apremiantes. Por eso, durante más de veinte años pude viajar con frecuencia a mi país, y sólo a partir de 1974 me vi obligado a considerarme como un exilado. Pero hay más y peor: al exilio que podriamos llamar físico habría de sumarse el año pasado un exilio cultural, infinitamente más penoso para un escritor que trabaja en íntima relación con un contexto nacional lingüístico" (Cortázar, 1984: 11).
} 
acontecimientos locales e internacionales del período. Es comparable en este sentido con la New School of Social Research de Nueva York dando refugio y aliento intelectual a quienes eran expulsados por el fascismo europeo de los años treinta, particularmente de Alemania y más específicamente de los procedentes de Frankfurt. Si en el caso norteamericano los frankfurtianos complementaban el desarrollo de una ciencia ya en marcha, en el mexicano la acogida del exilio de la dictadura franquista dará apertura a las labores de docencia e investigación en ciencias sociales trayendo Europa a América a través de la formación intelectual de profesionales de las ciencias sociales en obras fundamentales de la Sociología, como la traducción de Economía y Sociedad por el exiliado español José Medina Echevarría (Trindade, 2007).

Sin entidad de proyecto político como en México, la singular historia de Gino Germani en Argentina contribuye a medias y desde las antípodas ideológicas a esta épica del exilio. Entre emigrado y exiliado de Italia, Germani emprende una verdadera batalla de "neutralización" de la sociedad proponiendo y ejecutando una Sociología de oficio y con pretensión de fundamentarse exclusivamente en datos empíricos. Y lo hace combatiendo una narrativa autóctona de la sociedad fundada en el ensayo, una forma de relato de extendido y largo aliento en América Latina y que algunos piensan que hace a la naturaleza del continente ${ }^{6}$, que es propia del oficio intelectual contemporáneo ${ }^{7}$ y que es, incluso, una forma pionera de la Sociología ${ }^{8}$. La de Germani es una perspectiva del afuera que se legitima en la ideología cientificista de la época. Y con ella combate un estilo nacional sostenido en un "ensayismo esencialista" —piensa

\footnotetext{
${ }^{6}$ Arciniegas piensa al ensayo como algo consustancial a América por la mirada extrañada que el continente provoca desde su descubrimiento europeo: "América es ya, en sí, un problema, un ensayo de nuevo mundo, algo que tienta, provoca, desafía la inteligencia" (2012: 45). Género de extraños pero también y posteriormente de propios, puesto que "la revolución fue un ensayo intelectual que acabó siendo ensayo armado, y que así como nació de problemas estudiados por inteligencias atrevidas, culminó en las propias dudas republicanas que mantuvieron el tono de la revolución después de las victorias de San Martín, de Bolívar o de O'Higgins" (...) (2012: 47).

${ }^{7}$ Triviño Anzola recoge de Alfonso Reyes esta elocuente definición del género: "Este centauro de los géneros donde hay de todo y cabe de todo, propio hijo caprichoso de una cultura que no puede responder ya al orbe circular y cerrado de los antiguos, sino a la curva abierta, al proceso en marcha, al etcétera...cantado ya por un poeta contemporáneo preocupado de filosofía" (2012:86)

8 "La aparición de nuevas tierras, nuevos hombres, nuevas religiones, nuevos tipos de familia, nuevos sistemas de costumbres, domina en los días del descubrimiento y de la conquista, hasta el extremo de que entonces nace la sociología con varios siglos de anticipación a Comte y a Spencer" (p. 48). (Arciniegas, 2012: 48).
} 
Germani- que, en vez de producir conocimientos "originales", reproduce otros ya elaborados que poco efecto surten a la labor de modernización social con la que debe estar comprometida la Sociología. La solitaria posición del extraño de Germani y su ambiguo estatus entre inmigrante y exilado en un país donde la primera de esas figuras tiene una hegemonía simbólica avasalladora y donde la segunda es de exigua presencia, no se le hace óbice para producir una importante institucionalización de la Sociología en Argentina y situar la profesión en nuevos cánones y prácticas internacionales ${ }^{9}$.

¿Cuál es la distancia con el presente que constituye esta épica de la exterioridad, del desplazamiento de la pertenencia? ¿Qué acerca y qué aleja a nuestra figura-personaje actual de su referente pasado de exilio? Los aproxima sin duda una experiencia de alejamiento y de extrañamiento sobre origen y destino que predispone a una mirada atenta a significados alternativos al sentido común. Quizá también los empareja alguna pulsión de comparación, el hecho de hacer usos "espurios" de la historia y, en general, casi todo aquello que hace a los perfiles de la subjetividad desarraigada. Lo que los distancia es buena parte de lo que atañe más de cerca a la materia sociológica, lo que da cabida a ese presente espeso que es el hábitat contemporáneo de nuestro personaje en cuestión. La actual no es una figura que revele un malestar cultural como sí parecía hacerlo la generación del exilio. Sobre una y otra figura operan los términos de las recurridas, pero sugerentes y siempre a prueba de actualidad, comparaciones entre el exilio y la emigración. Por empezar, el malestar parece consustancial al desplazamiento que produce el exilio, mientras que a la emigración siempre la asiste una pluralidad de motivos que se corresponde con tiempos históricos de simulada ampliación del mundo de vida. Y por supuesto que es ese un mundo coloreado por escalas de desigualdad de diferentes motivos pero por ello también propenso al despliegue de dispositivos de expectativas para actores con agencia, reactivos a las señales de push and pull, aunque estén éstas dadas por ensoñaciones intelectuales sobre el norte, becas o simples viajes que se transforman en residencias. Y eso: si el del exilio es un sujeto de estructuras, el de la emigración parece que lo fuera de agencia. Al primero

\footnotetext{
${ }^{9}$ He abordado la figura de Gino Germani en relación a las cuestiones apuntadas, a las clases medias en Argentina y al proceso de institucionalización de las Ciencias Sociales en Argentina en Irazuzta, 2008. Quien esto lea puede hallar allí referencias bibliográficas específicas sobre el autor, su obra y su gestión académica en Argentina.
} 
nos lo representamos como habitante incómodo de tiempos políticos, en tanto que al segundo como agente inquieto de momentos económicos. Quizá sea porque las estructuras tienen mayor poder de seducción para la Sociología, o que tienden a primar en la historia de su debate teórico, que la generación del exilio guarde una relación épica con respecto a la generación de la emigración, que ésta aparezca frecuentemente subordinada en las escalas de glamour de las movilidades de poblaciones y que, por tanto, aquélla sea el referente encantado de las representaciones sobre las perspectivas del extraño.

\subsection{Militantes y sujetos; escritores y académicos}

Si es que la noción de generación ha venido impulsando implícitamente hasta aquí el hilo de las argumentaciones, me atrevo a sugerir que la de la emigración, no obstante su encarnación de la agencia, está compuesta por unos individuos que parecen más sujetos que los de la generación del exilio. Son en primer lugar sujetos por el propio zeitgeist de su tiempo, ese que surte al presente de muchas más preocupaciones individuales que colectivas, que concentra en el propio individuo, en el sujeto, la historicidad que en otros tiempos se alojaba en las utopías sociales, en la Ilustración primero, en el comunismo después. No obstante, en la otra cara de la subjetivación, aquella que la relaciona con la sujeción, nuestro personajefigura es también en parte sujeto de la misma relación histórica que lo vincula con la generación precedente, de ese lazo de carisma que lo sitúa en posición de afinidad electiva. La del exilio es la generación asociada a la liberación: es portadora y hacedora de ese compromiso sartreano que le obliga a ser libre, que hace de la escritura un arma y modalidad de combate por la liberación. Se da a ésta de la misma forma que el ser religioso a la fe y es de escaso titubear en la definición de la realidad social. Su ética es más de la convicción que de la responsabilidad y su acción se orienta más por valores que por fines (Dubet, 1989).

El hacer del académico emigrado actual no desconoce este origen pasional pero hace del compromiso vocación y de ésta profesión. Así, en su cotidianeidad, la del académico emigrado es una generación sujeta a una maquinaria institucional de producción de oficio que ha visto aumentar sus stocks en los últimos años al punto de generar excedentes y en algunos casos con esas cotas de exportación que hacen la llamada "fuga de cerebros". Nuestro objeto está hecho de sujetos de unas ciencias sociales o humanidades que se pretenden más científicas que en otros tiempos y que 
por ello entienden y disponen de una serie de instrumentos de medición de la producción que surten de motivos prácticos y de objetivos cercanos a la vida de los nuevos sujetos académicos. Sus ciencias son quizá más democráticas y menos elitistas que las de sus predecesores, pero por eso más masivas, menos glamurosas y con muchos más dispositivos de ordenación que califican la producción. En ese contexto, el investigador contemporáneo necesita conducirse con astucia por un camino que, de otra forma, lo arrima de seguro a las antípodas de esa deontología intelectual desinteresada que se representa como precedente y típicamente frankfurtiana.

Los más nuevos son unos sujetos fundamentalmente universitarios: gente que bien ha podido dejar su país - y asi lo han hecho todos a los que nos referimos - pero que raramente ha abandonado la universidad desde sus más imberbes años de formación. Seguramente ya no están en "su" universidad pero ha sido ésta la que le ha permitido pasarse a/por otra(s). La universidad es su mundo, su "mundo aparte" desde el que hace y ve mundo y quizá por ello, a diferencia de su referente pasado, el personaje figura que retratamos es un ser poco sujeto a esas dos instancias que hacen al mundo: el mercado y la política. No son tan escritores como para conducirse en el terreno de las ficciones ${ }^{10} y$ dirimir sus destrezas en el mercado editorial, pero tampoco menos como para ser meros escribas de príncipes: política y mercado son los límites modernos de nuestro tipo ideal. En este porte weberiano, el personaje en cuestión habita en esa brecha elástica y escolástica que suele legitimar su existencia con el epíteto de "académica"11.

Pero mercado y política son los flancos del acecho para el académico, científico o investigador actual: nuestra figura asiste, con mayor o menor

\footnotetext{
10 "Por 'escritor' entiendo sobre todo al novelista y al cuentista, es decir a los escritores de invención y de ficción; a la par de ellos incluyo al poeta, cuya especificidad nadie ha podido definir pero que forma cuerpo común con el cuentista y el novelista en la medida en que todos ellos juegan su juego en un territorio dominado por la analogía, las asociaciones libres, los ritmos significantes y la tendencia a expresarse a través o desde vivencias y empatías". (Cortázar, 1984: 10).

${ }^{11}$ La apreciación quizá provenga de la parte mexicana de mi ascendencia. En México "lo académico" tiene acepción - social, más que lingüísticamente reconocida- de sector, de sector o ámbito social, así como el sector político, empresarial o clerical. Quizá la cosa provenga de una tradición nacional de diferenciación social corporativa en la que la clase intelectual (académica) ocupó o se reservó un lugar destacado. Sea lo que sea, en el contexto azteca, "académico" provee un lugar de identificación, e incluso un rol social, de más diáfana identificación para lo que estamos definiendo.
} 
presencia, prestigio mediante, a los días críticos de la ética académica del desinterés. Padece $-y$ lo sabe, y se queja... ${ }^{12}-$ una pérdida de la autonomía académica que a veces imagina plena en la generación que le precede. En sus condiciones actuales, sus problemas sociológicos corren peligro de ser gobernados por problemas sociales, sus investigaciones pueden no prosperar si no cuentan con el aval de agentes "externos" con alguna causa práctica; su práctica puede llegar a entenderse como productora de "buenas prácticas".

Y aún así, nuestro personaje sigue contando con espacio para poner en juego la subjetividad en los objetos que toca. Y es especialmente propenso a ello cuando su figura se compone como personaje de dos mundos, cuando pone en relación los lugares, cuando habla de y desde lugares y cuando lo imaginamos como integrante de ese lugar de por sí dislocante que es la diáspora...

\subsection{Pero no constituyen diáspora, aunque pertenecen a su tiempo y tienden a ser interpelados como miembros de tal(es)}

La generación anterior se arrimó a definirse desde allí. Cortazar declaraba en sus tiempos de exilio que "(a)I tocar el problema del escritor exilado, me incluyo actualmente entre los innumerables protagonistas de la diáspora" (Cortazar, 1984: 10). Sin duda la de la diáspora es una imagen socorrida para la profesión intelectual. La experiencia judía está ahí para mostrar que lo fundamental del pensamiento occidental moderno está producido en condiciones de dispersión. Pero los tiempos de Cortázar no eran ni los mejores ni los más prolíficos para la propia idea de diáspora, como sí en cambio lo serán los que vive nuestra generación en cuestión. Durante aquellos tiempos más vivaces del estado-nación, la diáspora era una anomalía del sistema internacional, un estado negativo (Schnapper, 1999), del estado y de quienes se veían alejados de él, que lo estaban, además y por lo general, de esa forma doliente que encarna el exilio. No es el caso de los contemporáneos que habitan lugares dispersos puesto que éstos son

\footnotetext{
${ }^{12}$ y lo investiga. A sabiendas de la reflexividad de este cometido, conciente de que, al hacerlo, al indagar en las condiciones sociales de la producción de conocimiento científico, de someter ese mundo a la exploración y al análisis, ha abierto la caja de Pandora desentrañando asi su gramática y con el riesgo de reducir la vida científica a la mera vida social, "con sus reglas, sus presiones, sus estrategias, sus artimañas, sus efectos de dominación, sus engaños, sus robos de ideas, etcétera"; en definitiva, su campo (Bourdieu, 2003: 14).
} 
los espacios más normales de la era transnacional ${ }^{13}$. Desde estas nuevas diásporas se ejerce gran parte de la crítica al estado-nación ${ }^{14} y$, ubicados en ese des-lugar de la política moderna, los sujetos pueden armarse de razones para re-construir su identidad, para situarse como minorías y adquirir así potencialidad de movilización e influencia social en origen y destino (Clifford, 1999).

Pero nuestros personajes actuales no constituyen diáspora: no hay entre éstos una enunciación de la pertenencia que lo permita; no se pronuncian como colectividad; no existe tampoco un motivo unívoco de emigración que califique el desplazamiento y facilite así la construcción de un hito fundacional; no hay tampoco un rubro de dedicación cuantioso que le dé a quienes emigraron el empaque de "población". Pero hay, como decíamos, un tiempo histórico que es terreno fértil para que las diásporas germinen y que lo hagan sobre motivos variados que califican poblaciones más allá incluso de lo que constituía - y mayoritariamente constituye hoy - a las diásporas, es decir, la pertenencia nacional. Las diásporas contemporáneas se deslizan por ese declive de la modernidad que, de la razón, el progreso y la estabilidad, se inclina hacia la fragmentación, la hibridez, la fluidez de las identidades y casi todo lo calificado como "trans". Y así también acompasan el devenir transnacional del capital: pertenecen a la generación de la economía y por lo tanto se hacen sobre migraciones que son movilizaciones de fuerza de trabajo, que son constituidas como poblaciones, que pueden vivir más o menos al margen de -o con reconocimientos alternativos a - los de la ciudadanía moderna pero que, fundamentalmente, son capaces de habitar más de un lugar. Las diásporas rompen con el canon moderno de la asimilación en tanto que sus sujetos pueden ser y sentirse parte de dos sociedades al mismo tiempo y derivar de esta relativa ubicuidad razones y comportamientos instrumentales (Portes y DeWind, 2004). Y no sólo para los actores diaspóricos. También para los gobiernos de un lado y otro, la diáspora se ha vuelto un lugar relativamente común. Sobre todo para los de aquellos estados que producen ingentes emigraciones, ese espectro de origen que es la nación se les torna con frecuencia un motivo válido para seguir gobernando a estas poblaciones exudadas bajo la fórmula de "nacionales en el exterior". Es desde luego un motivo eficaz para esas zonas gruesas y más visibles de la economía que

\footnotetext{
${ }^{13}$ La diáspora es, según Tölöyan, la "comunidad ejemplar del momento transnacional" (1996: 20).

${ }^{14}$ Y de paso a las mismas ciencias sociales (Cf.: Wimmer y Glick Schiller, 2002). 
constituyen a las poblaciones más cuantiosas, pero también para las menos, como la de los científicos y académicos que suelen ser interpelados desde aquellas agencias científicas nacionales que reconocen sus trayectorias desplazadas y les proponen dobles inserciones científicas. Más que como una intervención humanitaria frente al desarraigo, operan sobre un cálculo de reversión en "capital humano" de fallidas "inversiones" pretéritas. Programas como el Raíces del Conicet de Argentina; Red de Talentos del Conacyt mexicano o Científicos y Tecnólogos Uruguayos en el Exterior, hacen llamados a los emigrados para la formación de redes, para la colaboración con instituciones y profesionales locales y, en general, para integrarlos a esa suerte de economía de vínculos tan propia de los tiempos transnacionales y de los que la diáspora es su insumo demográfico.

Pero la diáspora no es solamente reveladora de fenómenos meramente agregativos. Su vivencia propicia experiencias subjetivas que hacen a ese "nosotros descentrado" que le es tan propio. Emana de allí una narración individual, como lo recoge Brah al tratar de la autobiografía en la diáspora, que se pretende significativa de la rememoración colectiva y analíticamente promisoria de las relaciones entre afecto, modalidades psíquicas, relaciones sociales y políticas (Brah, 1996).

\section{Y en este punto me Sitúo. Dislocaciones}

\footnotetext{
"La fortaleza e independencia del saber psicológico estriba en que ha sustraído la posición humana del alcance de la geometría y de las oficinas de empadronamiento. Por medio de análisis psicológicos, a la pregunta dónde se encuentra un sujeto se le han dado respuestas que desmienten la evidencia física y civil. Sólo los cuerpos de los muertos pueden localizarse sin ambigüedad" Peter Sloterdijk, Esferas I, Madrid, Siruela, $5^{\text {a }}$ edición, 2014. p. 85.
}

Sin pretender ampararme en ningún tipo de saber -menos psicológicoesta parte del texto se cuela en esa suerte de fisura entre lo físico y lo civil, y lo hace no sin ambigüedad. Lo hace, o pretende hacerlo, desde el sujeto y desde el objeto, desde esa ambigüedad que muestra subjetivos a los objetos. Yendo y viniendo entre uno y otro, en lo que sigue relato mis dislocaciones académicas y doy cuenta del equipaje de temas, conceptos y objetos que me acompañan, de lo que abandono o incorporo en cada uno de mis desplazamientos. Son tres las locaciones geográficas: Argentina como origen, País Vasco como primer destino y México, mi lugar actual, como segundo. Y dos son las disciplinas desde la que ejerzo, con diferentes 
énfasis según los lugares: la Ciencia Política y la Sociología. Entre estas disciplinas y aquellas geografías diría que se ubican las locaciones que constituyen mi particular dislocación. Y el resultado, más o menos intencional, es una visión de objetos descentrados con respecto a unos y a otros lugares y saberes.

Aunque de preferencia esquivo a las identidades disciplinarias, soy de una y de otra cuando la institución universitaria me hace a sus normas: mis dos anclajes latinoamericanos, Argentina durante mis años de formación inicial en la universidad y México en mi ejercicio docente actual, me ubican en la Ciencia Política. Mi formación doctoral en la universidad española, justo en el medio de esos destinos americanos, me hace sociólogo. Y entre una y otra disciplina, que es también como decir entre unos lugares y otros, no soy ajeno al ánimo que suele ser propio de las almas desplazadas, la nostalgia: siendo politólogo en América Latina me atrae más la vida social silvestre que la que hace la norma institucional; haciendo de sociólogo en Europa y sobre Europa he colaborado en investigaciones desde las que me ha interesado ver la vida social que se forma del despojo institucional. Y supongo ya desde un híbrido disciplinario, desde Europa viendo América me he encontrado en situación de cruzar miradas sobre lo que es normal en un lado y en otro: bien las tramas narrativas de la nación en Argentina, tema desclasificado de las preocupaciones de las ciencias sociales rioplatenses en los años 90 y en cambio central en las agendas europeas; bien sus clases medias en la constitución de esas narrativas. Desde México viendo México, mi posición actual, me inquietan las situaciones de gobierno de lo anómalo en el fenómeno de constitución de "su diáspora" en Estados Unidos. En todos los casos, en un lado y en otro, la preocupación común se gesta en la intersección de dos temas que me interesa sobredimensionar: la identidad colectiva, como los diversos sentidos y pronunciamientos del nosotros, y el desplazamiento de poblaciones, como situación en la que se generan esos sentidos y pronunciamientos. Y puesto todo ello a detalle, podría reconstruir mi paralaje como sigue:

\subsection{Argentina desde Europa}

Son los años de mi formación doctoral, algo esquiva con respecto a lo que desde los imaginarios académicos rioplatenses deberían ser los centros de prestigio al respecto. Sin embargo el destino europeo parecía atinado teniendo en cuenta mis inquietudes para una futura tesis doctoral: el 
nacionalismo en Argentina luego de lo que, interpretaba por entonces, había sido su manifestación más patológica en la Guerra de Malvinas. La llegada fue a un lugar de expresión fractal en ese sentido. El del País Vasco era un nacionalismo de unas formas insospechadas desde América: periférico con respecto a otro central; sin estado; de una raigambre sin experiencia de desarraigo, es decir, étnico $y$, visto con los ojos de la modernidad americana, sospechosamente telúrico. La guía para la lectura de todo ello en la universidad, las pautas para constituirlo en fenómeno, fueron a partir de la identidad colectiva. Tema aún en boga por entonces en las ciencias sociales europeas luego de que algunas de las metrópolis del continente viejo experimentaban en casa los efectos inmigratorios de la descolonización. Desde la identidad colectiva, la superficie política del nacionalismo podía descomponerse en multiplicidad de prácticas cotidianas que producian y reproducian aquello $y$, entre aquel nivel de evidencia y este otro más o menos oculto entre las prácticas sociales de la vida diaria, experimentaba yo, no sin dificultad, las primeras marcas de un doble mestizaje: el de la Ciencia Política y la Sociología y el de un americano de orígenes europeos en Europa.

La tesis no podía sino ser la expresión de esta experiencia convulsa y de esa cierta altivez que da en ocasiones el posicionamiento extraño, en un lugar y en otro. El tema era revelador de ese cruce y de ese mestizaje. Incitado en parte por los imaginarios locales sobre los procesos de construcción de la nación en América Latina y en otra parte no desdeñable por una bibliografía que, con Benedict Anderson o Eric Hobsbawm entre otros, producía interesantes trabajos empeñados en reconstruir las narrativas de la nación, sus mecanismos y procesos de producción y reproducción, me dispuse a hacer lo propio con Argentina. La cosa fue sobre el relato del crisol de razas a través de una representación ritual de las colectividades de los inmigrantes llegados al país fundamentalmente en el siglo XIX y, en parte no desdeñable por mi amistad con colegas antropólogos, tuvo también su deriva en las condiciones festivas de producción de sacralidad en las sociedades democráticas.

De regreso a Argentina luego de concluida mi tesis doctoral, especulando ya en los mercados académicos de becas que no se encontraban tan desarrollados durante mis años de formación doctoral, preparé un proyecto sobre la vida asociativa contemporánea de uno de sus grupos de inmigrantes que había visto antes ritualizando su argentinidad de crisol. La especulación se inscribía en la estela de subvenciones y financiamientos a 
la investigación que se daba en esa suerte de celebración neocolonial del Quinto Centenario, cuando también los nacionalismos del Estado español buscaban proyectarse resaltando su lugar glorioso en América. El proyecto no prosperó en financiación por el lado europeo pero en cambio sí por el argentino. Con una beca posdoctoral del CONICET inicié una investigación sobre la colectividad vasca de la ciudad de Buenos Aires guiado por dos improntas principales: por un lado, como resultado de mi propio avatar becario, me interesó contrastar las visiones desde la metrópoli de estos grupos de desplazados de repente recordados allí y sempiternamente olvidados desde aquí, en Argentina. Una identidad ya casi anodina en América que, a partir de la otra gran impronta que hacía relevante el tema, era puesta en valor en el País Vasco: la diáspora. Pero la diáspora no emanaba como una reivindicación del grupo supuestamente disperso; era en cambio una forma de interpelación desde la metrópoli, un recurso aditivo para la identidad original que eventualmente podía contribuir a mitigar el esencialismo de algunos reclamos nacionalistas señalando otra manera más de "ser y sentirse vasco" capaz de, si no prescindir, al menos competir con los diacríticos fundamentales en el País Vasco, la lengua y principalmente el territorio. La diáspora, proveedora como concepto de más de una metáfora de hibridación, mestizaje, transnacionalismo y difusión ${ }^{15}$, hacía además una propuesta promisoria para la hechura de globalización en una época de incesante fluido de capitales e imaginarios culturales entre Europa y América Latina que las administraciones metropolitanas sabrian aprovechar bajo sus propios criterios de producción.

De todo ello, renuente a optar por la especialización étnica en mi trabajo de investigación y dedicarme a lo que iba constituyéndose como campo alrededor de los estudios sobre los vascos en América, me quedé con el concepto y la idea de diáspora. Después de la crisis argentina de 2001, especialmente revulsiva en las migraciones académicas del país, con ello parto hacia México.

\subsection{México desde México}

Mi llegada a México se da luego del agotamiento y la crisis de aquel fluir global austral $y$, en cambio, en el marco de "programas de

\footnotetext{
${ }^{15}$ Se ha subrayado la significancia de que el término diáspora (al menos en inglés y otras lenguas de origen indoeuropeo) comparta la raíz demarcada por las consonantes spr con sugerentes palabras como spore, disperse, spread y sperm (Tôlôyan, 1996: 10).
} 
internacionalización" de una universidad privada de la América Latina del norte. Estas geografías y prácticas más cercanas al capitalismo académico me mantuvieron por algunos años dedicados a la docencia y a la gestión universitaria en un departamento de Relaciones Internacionales cuyo trabajo consistía en parte en la producción de internacionalización (económica, política, cultural, académica...) a través de la preparación de licenciados. Una suerte de "globalización desde abajo" (Portes, Guarnizo y Landolt, 2003) pero en este caso "de élite": muchos de los graduados de nuestros programas académicos irían a ocupar los diversos departamentos de internacionalización de las empresas, algunos otros accedieron a cargos de algunas organizaciones internacionales, unos muy pocos a los viejos servicios diplomáticos del Estado mexicano, otros tantos a ser empresarios de alguna causa fundando una ONG y hasta otros a atender call centers de este próspero sector en este costado de la geografía global.

Pero el ímpetu de internacionalización empujaba también por entonces a la propia institución universitaria al desarrollo de "indicadores" en investigación, de tal forma que ello le permitiera posicionarse ante esas agencias acreditadoras y de rankings académicos que hacen a los "gobiernos por auditorías" (Rose, 1996) del sector. En ese contexto, se da mi ingreso al Sistema Nacional de Investigadores mexicano y, desde allí, retomo mis preocupaciones australes sobre la diáspora. La gran expansión del concepto, que había llegado incluso a producir un vacío semántico de la categoría, según se denunciaba en la bibliografía especializada, se extendía hasta el gran tema de las agendas científicas mexicanas: el de "su" migración en Estados Unidos. La diáspora deviene progresivamente una "categoría de prácticas" (Brubaker, 2005) y, en el caso de México, iniciando el nuevo milenio y desde una legitimidad de gobierno renovada, es practicada a través de la interpelación a su población en el país vecino para poder así insertarla en una economía de vínculos y de remisión en la que van quedando involucrados diversos agentes que hacen tanto a los grandes indicadores de la economía nacional (las remesas), como al desarrollo de las pequeñas comunidades de origen de los migrantes en una suerte de pretendido "efecto Tocqueville" sobre el desarrollo social deseable para México desde sus élites gubernamentales. Se trata de un gobierno sobre la dispersión, una acción gubernamental que se extiende hacia esas zonas dispersas de las poblaciones y el sentido y que sobrepasa los límites modernos de lo público y lo privado y del adentro y el afuera. La diáspora es así una especie de "topónimo" para poblaciones desplazadas 
que hallan en la dislocación, lo intersticial o lo transnacional su peculiar lugar de existencia. Y en el caso de México una forma renovada de afrontar su ya ancestral "transnacionalismo binacional y de frontera".

y así en el objeto como en el sujeto. Tanto por mi propia práctica académica, que desde entonces me mantiene en trabajos de colaboración a distancia con mis colegas del País Vasco y en ocasiones con argentinos, como por un mercado más desarrollado de becas, subvenciones y proyectos que vinculan investigadores de unos lados y otros, o por indicadores de productividad que pueden contabilizarse aquí y allá, mi experiencia académica se va haciendo a cierto habitus transnacional y deslocalizado.

\subsection{Europa desde Europa}

Desde Europa he visto Europa con becas, contratos temporales, subvenciones de proyectos de investigación o "rentas de garantía de ingreso". Y siempre desde el Centro de Estudios sobre la Identidad Colectiva que, a pesar de - o gracias a- sus propios avatares de dispersión por las movilidades de quienes formamos parte de su equipo de investigación, nunca ha dejado de ser el centro de mis dislocaciones; el norte de mi particular paralaje y la academia que me hace sociólogo. En estancias de investigación más o menos prolongadas o en la comunicación a distancia, mi trabajo allí ha sido y es casi siempre grupal y me ha arrimado a ver los procesos de construcción y reproducción de la identidad colectiva en las mellas de la institución.

Las investigaciones sobre la precariedad que llamamos "vital" para acercarnos con las dimensiones de este adjetivo a las limitaciones que hallan los sujetos para gestionar su autonomía en condiciones de desinstitucionalización, o las que tuvieron como objeto a la vulnerabilidad como una situación sobre la que muchos individuos o colectivos se constituyen como el Otro que es objeto de gobierno, o las que intentan desentrañar los mundos de vida y los dispositivos que se forman desde la figura de la víctima se han encaminado, desde diferentes vías, a ver la identidad en esos lugares clásicos de la desviación y la anomia que, en las condiciones contemporáneas de la crisis de lo social, parecen normalizarse. Entonces, desde aquí como sociólogo, la mirada se dirige hacia el reverso de la institución, hacia la vida social que genera su "declive", si se quiere incluso hacia los procesos de inversión de la ciudadanía en la proliferación de una serie de figuras que parecen 
constituirse en la falta.

Desde esta reversión de la normalidad en Europa he vuelto en ocasiones la mirada hacia América Latina para ver allí el estado de algunas expresiones de su normalidad. En parte importante imbuido por este tipo de estudios europeos y en otra parte no menor impresionado por lo que había motivado o hecho a la estructura de oportunidades para mi salida de Argentina -la sonada crisis de 2001-, me interesé también por sus clases medias. Más específicamente por el primer sociólogo de oficio en Argentina (Gino Germani) que, desde su hacer, hizo mucho a las representaciones sobre y a la mentalidad de este sector social normal tan frondoso estadística como espiritualmente. También comienzo a ver ahora algunos de mis asuntos de México desde estas perspectivas de las mellas en la normalidad. La diáspora lo es; y lo es especialmente en la condición de "ilegalidad" de muchos de los migrantes mexicanos en Estados Unidos, otra versión, si se quiere, del desafortunadamente amplio fenómeno de "desapariciones" contemporáneas en el país. En fin, desde mi locación en Europa veo aquí, y por proyección allá, las zonas y los objetos de sentido desinstitucionalizado, la vida social y los sujetos que se gestan y reproducen en el reverso de los derechos y los deberes que dieron forma al individuo y a la sociedad en la modernidad.

Estos tres vértices, y entre ellos idas y vueltas, dibujan el paralaje desde el que se han ido construyendo mis objetos de investigación. Por ellos transito practicando una suerte de migración blanca. "Blanca" porque no carga con los rigores de las migraciones que atraviesan la "línea de color" y, en cambio, está impulsada por las agencias que hacen a las prácticas académicas contemporáneas, que son transnacionales, relativamente deslocalizadas, hechas a las morfologías reticulares; más o menos accesibles al común del profesorado universitario... También "blanca" porque, en el nomadismo acotado de esos tres lugares, trabajo y vivo en una misma lengua; soy allí una especie de políglota de interior que procura ser tan tolerante como calculador ante las modulaciones diferentes y las arbitrariedades de sus usos distintos (Françoise Collin, en Braidotti, 2000). Podría decirse, sorteando las aduanas de palabras entre unos y otros lugares, que hago un uso modular del español, un uso que va perdiendo conciencia y adquiriendo consistencia a medida que me asiento en el tránsito entre estos tres vértices. 
Y en la superficie interior de este perímetro, el Atlántico, que por mucho tiempo ha visto el trasiego de no pocas vidas e ideas, que ha sido "negro" en la conexión con otro continente y en la mirada de intelectuales como Du Bois, que ha sido y es "blanco" en el cruce de perspectivas y miradas de una y otra de sus orillas con diferentes pesos e intensidades: desde Frankfurt a la América del Norte, o con Cortazar en la otra dirección, o con Germani y Lazarsfeld... También en el anonimato de esta versión más masificada y menos glamorosa en la que inscribo y escribo mi propia experiencia. Y es ello con la intención de que quien esto lea lo haga con una visión de conjunto de los textos que me acompañan en este número de Papeles; que estos materiales personales sean no más que insumo de una sociología de las formas académicas dislocadas que en este caso tienen como norte Latinoamérica; que mis experiencias hagan a ese anonimato que construye lo colectivo. Porque, después de todo, como según Borges (2006: 210) dice Abenjaldún "en las repúblicas fundadas por nómadas, es indispensable el concurso de forasteros para todo lo que sea albañilería".

\section{BIBLIOGRAFÍA}

Arditi, B., 2010, La política en los bordes del liberalismo, Gedisa, México.

Arciniegas, G., 2012, "Nuestra América es un ensayo", en Revista Anthropos, 234, pp. 45-53.

Borges, J.L., 2006, El Aleph, Emecé, Buenos Aires.

Bourdieu, P., 2003, El oficio del científico, Anagrama, Barcelona.

Brah, A., 1996, Cartographies of Diaspora. Contesting Identities, Londres, Routledge.

Braidotti, R., 2000, Sujetos nómades, Paidós, Buenos Aires.

Brubaker, R., 2005, "The 'diaspora' diaspora", en Ethnic and Racial Studies, 28, 1, pp. 1-19

Cortázar, J., 1984, Argentina: años de alambradas culturales, Muchnik editores, Barcelona.

Clifford, J., 1999, "Diasporas" en M. Guibernau y J. Rex (Eds.), The Ethnicity. Nationalism, Multiculturalism and Migration, Polity Press, Cambridge.

Dubet, F., 1989, "De la sociología de la identidad a la sociología del sujeto", en Estudios sociológicos, VII, 21, pp. 519-545.

Gilroy, P., 1993, The Black Atlantic: Modernity and Double Consciousness, Verso, Londres. 
Irazuzta, I., 2008, "Clases medias, política y sociedad en los inicios de la Sociología empírica en la Argentina", en Trayectorias, 10, 27, pp. 9099.

Lazarsfeld, P., 2001, "Memoria de un episodio en la historia de la investigación social", en Revista Española de Investigaciones Sociológicas, 96, 01, pp. 235-296.

Maquiavelo, N., 1992, El príncipe, Espasa Calpe, Madrid.

Portes, A., J. DeWind, 2004, "A Cross Atlantic Dialog: Progress of Research and Theory in the Study of International Migration", en International Migration Review, 38, 3, pp.828-851.

Portes, A., L. Guarnizo, P. Landolt, 2003, La globalización desde abajo: transnacionalismo inmigrante y desarrollo. La experiencia de Estados Unidos y América Latina, México, Flacso/Porrúa.

Rose, N., 1996, "The Death of the social? Re-figuring the Territory of Government", en Economy and Society, 25, (3), pp. 327-356.

Schutz, A., 1974, "El forastero. Ensayo de psicología social", en Schutz, A., Estudios sobre teoría social, Amorrortu, Buenos Aires.

Schnapper, D., 1999, "From the Nation-State to the Transnational World: On the meaning and Usefulness of Diaspora", en Diaspora. A Journal of Transnational Studies, 8, 3, pp. 225-255.

Scott, J., 1992, "Experience", en J. Butler y J.W. Scott, Feminists Theorize the Political, Routledge, Londres, pp. 22-40.

Tölölyan, K., 1996, "Rethinking Diaspora(s): Stateless Power in the Transnational Moment", en Diaspora. A Journal of Transnational Studies, 5, 1, pp. 3-35.

Triviño Anzonla, C., 2912, "De Montaigne a Arciniegas, la escritura y la construcción del ser americano", en Revista Anthropos, 234, 2012, pp. 86-94.

Trindade, H. (coord.), 2007, Las ciencias sociales en América Latina, Siglo XXI, México.

Véjar Pérez-Rubio, C. (coord.), 2008, El exilio latinoamericano en México, CEIICH-UNAM, México.

Weber, M., 2001, La ética protestante y el "espíritu" del capitalismo, Alianza, Madrid.

Wimmer, A., N. Glick Schiller, 2002, "Methodological Nationalism and Beyond: Nation-State Building, Migration and the Social Sciences", en Global Networks, 2, 4, Pp. 301-334. 
